Journal of

Applied Crystallography

ISSN 0021-8898

\section{Peter Goodman}

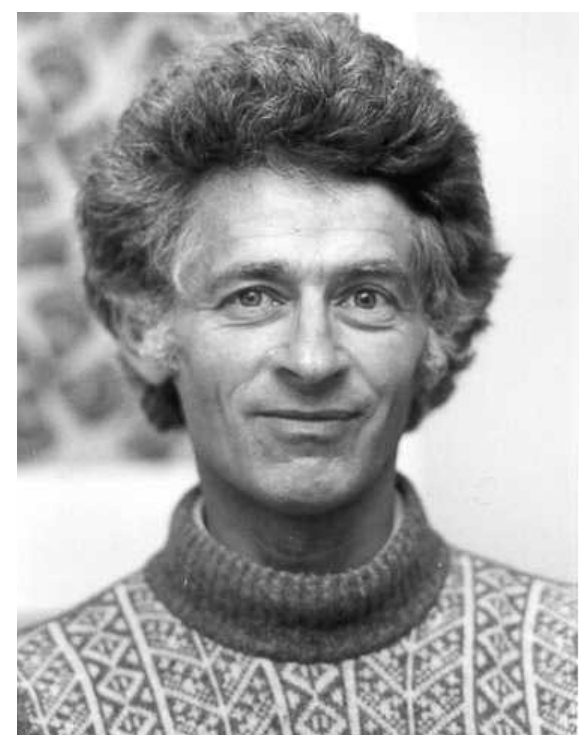

On March 26 1999, one of the pioneering scientists in the field of electron diffraction, Peter Goodman, passed away in Melbourne, Australia. His main and lasting contribution

\title{
crystallographers
}

was the revival and development of convergent-beam electron diffraction (CBED) into a crystallographic tool.

The CBED patterns that Peter and Gunter Lehmpfuhl obtained in 1965 marked the beginning of systematic application of this technique to determination of crystal symmetry and structure-factor refinement. Peter's interpretation of the symmetries appearing in CBED patterns, which was published in Nature (1974), opened up a new determination method of crystal point groups. The first result to be published (in 1964) from the work with Gunter on this question was in fact the observation (or confirmation) of the condition for dynamical extinction in kinematically forbidden reflections. This is now the fundamental method used for spacegroup determination. The space-group symmetry theory of the CBED method was described in the recent revision of International Tables for Crystallography, Volume B, by Peter. He was concerned with spacegroup determination until the end of his life - in particular he wanted to discover a distinguishing method of the two sets of space groups (I222 and $\left.I 2_{1} 2_{1} 2_{1}\right)$ and (I23 and $\left.I 2{ }_{1} 3\right)$. Just before his passing away, Michiyoshi Tanaka's team at length succeeded in solving the problem: the two space groups can be distinguished by the coherent CBED method.

Peter's contributions to the field of electron diffraction and structural studies are indelibly written into the history of the subject, and will be abiding. He was an enormously valued colleague, who had deep collaborations with many of the leading diffraction theorists of the day, including Alex Moodie, Gunter Lehmpfuhl and Jon Gjønnes. A comprehensive obituary of Peter Goodman can be found on the IUCr website, at http://www.iucr.org.

David J. H. Cockayne

Jon Gjønnes

Colin J. Humphreys

Gunter Lehmpfuhl

John Murphy

Uri Shmueli

John C. H. Spence

Michiyoshi Tanaka

Nicholas S. Witte 